\title{
Morphology and kinetics of susceptible and resistant Biomphalaria alexandrina hemocytes during the first week Original of exposure to Schistosoma mansoni miracidia
} Article

\author{
Safaa I Khedr
}

Department of Medical Parasitology, Faculty of Medicine, Alexandria University, Egypt

\begin{abstract}
Background: Few studies concerning Biomphalaria alexandrina (B. alexandrina) snail hemocytes' subpopulations, and their relation to the compatibility with Schistosoma mansoni (S. mansoni)' miracidia were performed. Manipulation of parasite development inside these snails could be applied as a control measure against schistosomiasis.

Objectives: Knowing that the snail hemocytes temporarily bind to the parasites, allowing the development of cercariae that are infective to the definitive host. This study aimed at studying the morphology and kinetics of diverse hemocytes of susceptible and resistant B. alexandrina and their participation in the snail early immune response after challenge by $S$. mansoni.

Material and Methods: Giemsa stained hemocytes were characterized using light microscopy. Total and differential hemocyte counts (THC and DHC) were calculated in the hemolymph of two groups composed of 60 susceptible and 60 resistant snails. Each group was further subdivided as 12 control pre-exposure snails (PE) and 48 post-exposure snails (PO) to $S$. mansoni at different time points ( $6 \mathrm{~h}, 1,3$ and 7 days). THC and DHC counts were recorded by a snail hemogram.

Results: Results revealed that granulocytes constituted the most common population all through the experiment with the large dense-granulated granulocytes subpopulation being the largest-sized cells detected. The highly reactive subpopulations that increased in number upon exposure to $S$. mansoni were the few-granulated and the large-granulated granulocytes, suggesting their possible participation in early parasite destruction.

Conclusion: The resulting hemograms helped determine the participation of hemocyte populations and subpopulations in the defense against $S$. mansoni, aiding in understanding snail compatibility patterns. Further studies to propagate transgenic B. alexandrina snails abundant in large granular granulocytes utilizing (gene editing) CRISPR-Cas9 technique are recommended. This would be required to spread schistosome resistance traits in snail populations, thus, contributing to reduced schistosomiasis transmission in the long run.
\end{abstract}

Keywords: Biomphalaria alexandrina, blast-like cells, differential hemocyte count, granulocytes, hyalinocytes, total hemocyte count.

Received: 19 October, 2020, Accepted: 24 November, 2020.

Corresponding Author: Safaa I Khedr, Tel.: +20 1203831492, E-mail: Siak_1380@yahoo.com

Print ISSN: 1687-7942, Online ISSN: 2090-2646, Vol. 13, No. 3, December, 2020.

\section{INTRODUCTION}

B. alexandrina snail acts as an obligate intermediate host for $S$. mansoni miracidia, a parasite that causes intestinal schistosomiasis, a major neglected tropical disease, that affects millions all over the world ${ }^{[1]}$. Different Biomphalaria species transmitting $S$. mansoni exist in Africa and South America. Among the African species, $B$. alexandrina snail acts as the main intermediate host in Egypt $\mathrm{t}^{[2]}$.

For completion of $S$. mansoni life cycle, mature eggs are excreted in the definitive host feces. On reaching freshwater, the eggs hatch releasing freely swimming miracidia which on penetration of the snail, stimulate the snail defense system. At the same time the parasite tries to escape the snail host weapons in order to propagate its life cycle ${ }^{[3,4]}$. Compatible snails allow successful schistosome development, while incompatible snails' internal defense system destroys the invading parasite ${ }^{[5]}$. The Biomphalaria internal defense system consists of humoral and cellular elements. Hemocytes populate the snail circulatory system and constitute the principal cellular defense line ${ }^{[6,7]}$. Hemocytes of resistant snails destroy parasite larvae by phagocytosing their tegument and producing reactive oxygen intermediates. Activation of the internal defense also occurs during parasite development inside susceptible snails, where, hemocytes temporarily bind to the parasites, allowing the development of sporocysts then cercariae. The latter are shed in freshwater to infect the definitive host $^{[5,8,9]}$.

Despite the considerable efforts spent on characterizing hemocytes in different mollusks, there are many controversies concerning their classification $^{[10]}$. Hemocytes of various Biomphalaria species have variable morphology and different 
subpopulations ${ }^{[11-13]}$. Nevertheless, several authors agreed that Biomphalaria hemocytes consist of two primary cell populations: granulocytes that are mainly involved in phagocytosis and cytotoxicity with generation of reactive ions from their cytoplasmic granules, and hyalinocytes that are less phagocytic due to absence of cytoplasmic granules ${ }^{[14-16]}$. A third hemocyte population, the blast-like cells, has been characterized. Being small cells with a large nucleus, they are thought to be the progenitors of the other populations ${ }^{[11,17]}$. Regarding B. alexandrina snails, previous research studied their hemocytes ${ }^{[18-21]}$, yet, information about the functional attributes of their populations and subpopulations in response to $S$. mansoni infection is still deficient.

Identification of $B$. alexandrina hemocyte dynamics is essential in understanding compatibility differences among various Biomphalaria species, which in turn can help in providing new approaches to break the Schistosoma transmission cycle inside its intermediate host ${ }^{[8,22]}$. Therefore, in the current work, the morphology of Giemsa stained B. alexandrina hemocytes and their participation in the early immune response of susceptible and resistant snails against $S$. mansoni miracidia were studied using light microscopy.

\section{MATERIAL AND METHODS}

This case-control study was conducted at the Medical Parasitology Department, Faculty of Medicine, Alexandria University, Egypt during the period from May to August, 2016.

Snails and parasite: $B$. alexandrina snails were originally obtained from water channels in Alexandria (Egypt) during the year 2011. Since then, snails were maintained under suitable environmental conditions; breeding in aquaria containing dechlorinated tap water at $26^{\circ} \mathrm{C}$, and were fed lettuce leaves supplemented with fish food and calcium carbonate ${ }^{[4]}$.

S. mansoni strain sympatric to the bred B. alexandrina strain was used in this $s{ }^{2} y^{[23]}$. The parasite was originally obtained by shedding cercariae from naturally infected $B$. alexandrina snails. Maintenance of $S$. mansoni life cycle was conducted between the laboratory-bred snails and male Swiss-albino mice. Using the paddling technique, each mouse was infected with 120 cercariae $^{[24]}$. Seven to eight weeks postinfection, S. mansoni eggs obtained from mice, were exposed to direct sunlight to stimulate miracidial hatching. Two-months-old snails were challenged by individual exposure to 10 active miracidia ${ }^{[8]}$.

For separation of susceptible and resistant snail stocks, snails that showed high infection rates were isolated and reared singly for self-reproduction and their progeny was identified as the susceptible stock. While snails that remained uninfected after two exposures were isolated and reared singly for self-reproduction. Their progeny was the resistant stock ${ }^{[9]}$. From the two progenies, 60 susceptible and 60 resistant snails, sized about $8 \mathrm{~mm}$, were selected to comprise the susceptible and the resistant groups, respectively. In each of the two groups; twelve snails remained unexposed to infection ( 2 control subgroups). The remaining 48 snails in each of both groups were exposed individually to ten $S$. mansoni miracidia (2 exposed subgroups).

Hemolymph collection: Snails shells were wiped with $70 \%$ alcohol and dried with an absorbent paper. Hemolymph collected by cardiac puncture was placed in a siliconized tube in an ice bath to prevent cellular aggregation and to permit the settling and removal of any debris ${ }^{[9]}$. Hemolymph collection was performed at $6 \mathrm{~h}, 1 \mathrm{~d}, 3 \mathrm{~d}$, and $7 \mathrm{~d}$ post individual exposure (PO) to $10 \mathrm{~S}$. mansoni miracidia. These were compared to the control unexposed subgroups that were considered as the base line hemocyte counts ( 0 hour). The experimental design is described in figure (1).

Total hemocyte counts (THC): The number of hemocytes in $1 \mu \mathrm{l}$ of fresh hemolymph from each of the 12 individual snails (biological replicates) was counted using a Neubauer chamber under bright-field microscopy at the high-power magnification (X40). The count was repeated 6 times for each sample at each time point (technical replicates) ${ }^{[11]}$.

Hemocyte characterization: One $\mu$ l of the hemolymph from each snail was allowed to dry on a microscope slide for $30 \mathrm{~min}$, then, fixed in methanol for $10 \mathrm{~min}$, stained with Giemsa (diluted 1:9 in buffered distilled water) for 10-15 min. The slides were then washed with buffered distilled water and dehydrated in ethanol, then examined using bright-field microscopy at X100 magnification for morphological identification of the cells. To determine the nucleus/cytoplasm (N/C) ratio, the cellular and nuclear dimensions of 50 cells from each subpopulation were measured using an eyepiece micrometer. The measurements $(\mu \mathrm{m})$ were taken at the broadest diameter, excluding the pseudopodia and filopodia $^{[11,25]}$.

Differential hemocyte counts (DHC): To determine the mean value of each hemocyte population and subpopulation, the numbers of morphologically different hemocytes were counted in Giemsa stained smears, from the same samples that were used for THC. Based on counting $\sim 200$ cells/snail, the mean value of each hemocyte type was calculated. The same counting methodology was repeated 6 times (technical replicates) for each snail.

Statistical analysis: Quantitative data were analyzed using $F$-test (ANOVA) and post-hoc tests. Data are expressed as means \pm standard deviation (SD). $P<0.05$ was considered statistically significant. Statistical 


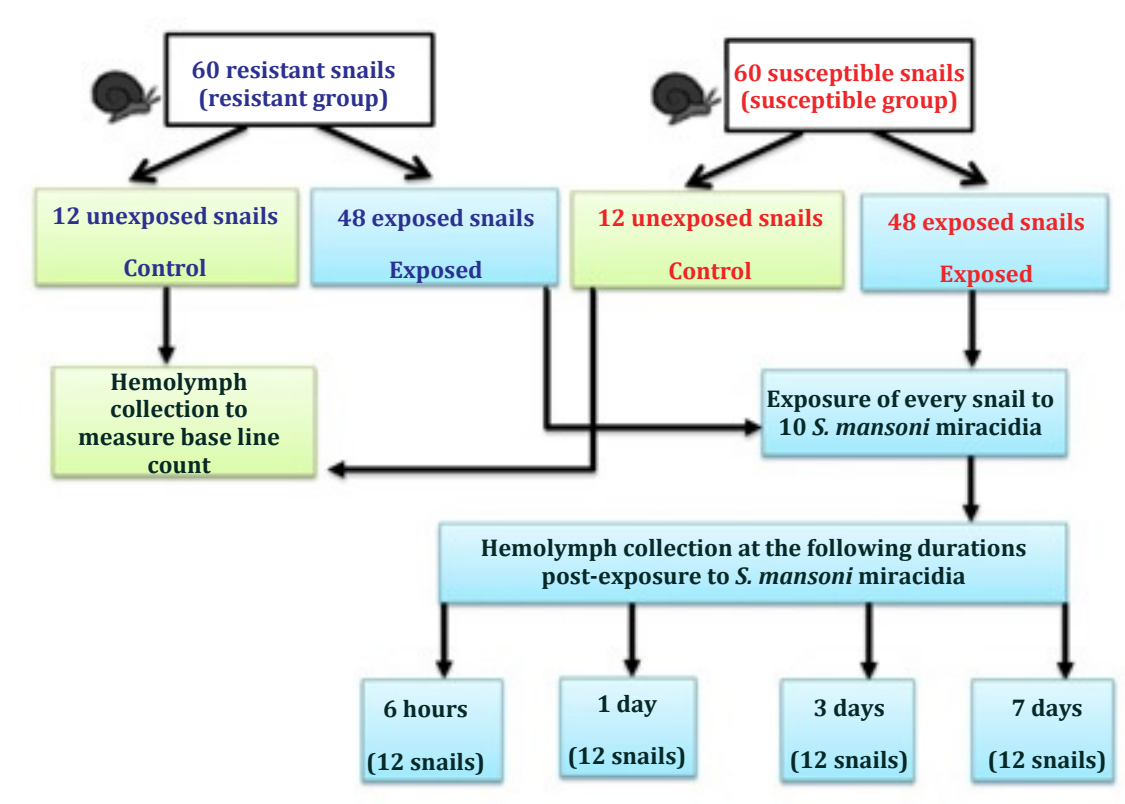

Fig. 1. Experimental design.

calculations were performed using IBM SPSS software package version 20.0 (SPSS Inc, Chicago, IL, USA).

Ethical approval: All experiments were conducted abiding with institutional ethical guidelines for animal use in research. The study protocol was approved by the Ethics Committee of Faculty of Medicine, Alexandria University, Egypt.

\section{RESULTS}

Total hemocyte counts (THC): The mean THC of susceptible unexposed control snails was $406.17 \pm 12.51$ cells/ $\mu \mathrm{l}$, which was significantly lower than the mean THC of the resistant unexposed controls $(424.83 \pm 6.97$ cells $/ \mu \mathrm{l}$ ). After exposure to $S$. mansoni, THC showed remarkable changes in susceptible and resistant groups, at different experimental time periods. In both groups, the THC was significantly lower than that of the corresponding control group at $6 \mathrm{~h} \mathrm{PO}$. This was followed by an increase at the $1^{\text {st }}$ day post exposure (DPO) and maintained at a high level till the end of the experiment. Full data concerning THC are shown in figure (2). Table (1) displays the intergroup

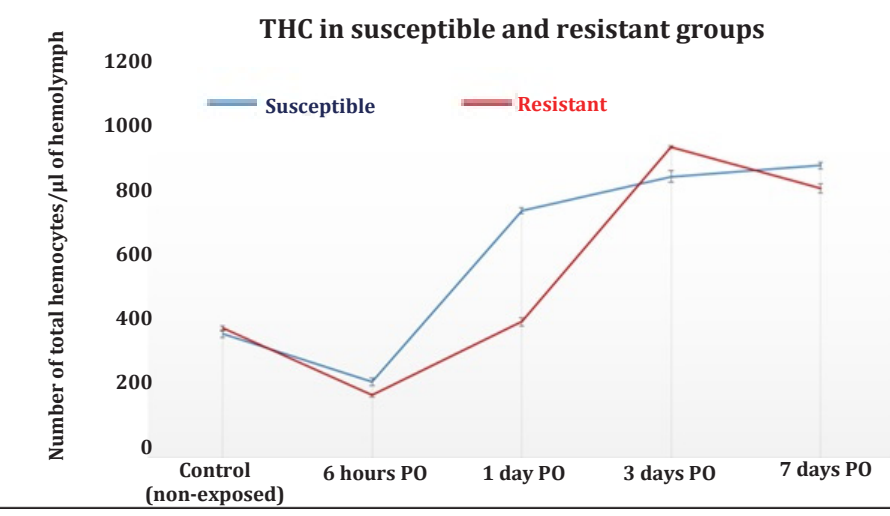

comparison between THC and DHC of susceptible and resistant groups at different time periods PO to $S$. mansoni miracidia.

Hemocyte characterization (morphology): Based on nucleus/cytoplasm sizes, the N/C ratio, the presence of cytoplasmic granules and cytoplasmic extensions, three main hemocyte populations were identified in $B$. alexandrina hemolymph. These were: blast-like cells, hyalinocytes, and granulocytes ${ }^{[11]}$. Table (2) shows the hemocytes measurements.

Population I: Blast-like cells (BL) were the smallest cells with a mean diameter of $4.0 \pm 0.2 \mu \mathrm{m}$. They were round, lymphocyte like, having a relatively large, darkstained basophilic central or eccentric nucleus, which occupied almost the entire cell with a thin rim of blue cytoplasm. Hence, they had the highest $\mathrm{N} / \mathrm{C}$ ratio of about $0.8 \pm 0.03$, which was significantly different from other populations. The cytoplasm did not show any extensions (Fig. 3). Two subpopulations were identified: agranular blast-like cells with no granules (Ag BL) or subpopulation Ia, and granular blast-like cells (GBL) or subpopulation IIa that contained basophilic granules.

Fig. 2. Intergroup comparison between the total hemocyte count (THC) of susceptible and resistant groups before and after exposure to S. mansoni miracidia. PO: Post-exposure to $S$. mansoni. 
PARASITOLOGISTS UNITED JOURNAL

Table 1. Intergroup comparison between the means of THC and DHC of susceptible and resistant groups at different experimental periods.

\begin{tabular}{|c|c|c|c|c|c|c|c|c|c|c|c|}
\hline \multirow{3}{*}{\multicolumn{2}{|c|}{$\begin{array}{l}\text { Hemocyte } \\
\text { Pop \& } \\
\text { SubPops }\end{array}$}} & \multicolumn{10}{|c|}{ Time of exposure } \\
\hline & & \multicolumn{2}{|c|}{ Control (0 hour) } & \multicolumn{2}{|c|}{6 hours PO } & \multicolumn{2}{|c|}{1 day $P O$} & \multicolumn{2}{|c|}{3 days $P O$} & \multicolumn{2}{|c|}{7 days $P O$} \\
\hline & & $S$ & $\mathbf{R}$ & $\mathbf{S}$ & $\mathbf{R}$ & $S$ & $\mathbf{R}$ & $\mathbf{S}$ & $\mathbf{R}$ & $\mathbf{S}$ & $\mathbf{R}$ \\
\hline \multirow{2}{*}{\multicolumn{2}{|c|}{ THC }} & $406.17 \pm 12.51$ & $424.83 \pm 6.97$ & $250 \pm 11.82$ & $205.83 \pm 4.84$ & $810.67 \pm 8.91$ & $446.83 \pm 13.1$ & $923.33 \pm 18.51$ & $1020.67 \pm 13.6$ & $959.17 \pm 9.87$ & $884 \pm 14.04$ \\
\hline & & \multicolumn{2}{|c|}{$P=0.02^{*}$} & \multicolumn{2}{|c|}{$P=0.00^{*}$} & \multicolumn{2}{|c|}{$P=0.00^{*}$} & \multicolumn{2}{|c|}{$P=0.00 *$} & \multicolumn{2}{|c|}{$P=0.00^{*}$} \\
\hline \multirow{6}{*}{$\begin{array}{l}\text { Pop } \\
\text { I } \\
\text { (B) }\end{array}$} & \multirow{2}{*}{ TBL } & $39.83 \pm 1.17$ & $42.67 \pm 3.27$ & $29 \pm 5.33$ & $37.67 \pm 2.88$ & $99 \pm 4.29$ & $83.83 \pm 2.71$ & $131.17 \pm 5.46$ & $128 \pm 4.03$ & $133 \pm 2$ & $113.33 \pm 4.37$ \\
\hline & & \multicolumn{2}{|c|}{$P=0.08^{*}$} & \multicolumn{2}{|c|}{$P=0.02^{*}$} & \multicolumn{2}{|c|}{$P=0.00^{*}$} & \multicolumn{2}{|c|}{$P=0.05^{*}$} & \multicolumn{2}{|c|}{$P=0.00^{*}$} \\
\hline & \multirow{2}{*}{ AgBL } & $33.17 \pm 2.56$ & $36.17 \pm 3.19$ & $22 \pm 3.79$ & $28.67 \pm 2.73$ & $72.17 \pm 4.26$ & $60 \pm 2.61$ & $108.67 \pm 6.74$ & $102 \pm 1.9$ & $107 \pm 3.16$ & $96 \pm 2.97$ \\
\hline & & \multicolumn{2}{|c|}{$P=0.09^{*}$} & \multicolumn{2}{|c|}{$P=0.02 *$} & \multicolumn{2}{|c|}{$P=0.00 *$} & \multicolumn{2}{|c|}{$P=0.01 *$} & \multicolumn{2}{|c|}{$P=0.00^{*}$} \\
\hline & \multirow{2}{*}{ GBL } & $33.17 \pm 2.56$ & $36.17 \pm 3.19$ & $22 \pm 3.79$ & $28.67 \pm 2.73$ & $72.17 \pm 4.26$ & $60 \pm 2.61$ & $108.67 \pm 6.74$ & $102 \pm 1.9$ & $107 \pm 3.16$ & $96 \pm 2.97$ \\
\hline & & \multicolumn{2}{|c|}{$P=0.79^{*}$} & \multicolumn{2}{|c|}{$P=0.02^{*}$} & \multicolumn{2}{|c|}{$P=0.01 *$} & \multicolumn{2}{|c|}{$P=0.24$} & & $.00^{*}$ \\
\hline & $T U$ & $129 \pm 6.16$ & $119.5 \pm 1.76$ & $52.17 \pm 5.19$ & $75.67 \pm 4.63$ & $134.67 \pm 3.78$ & $161.5 \pm 3.73$ & $218.83 \pm 10.57$ & $100.17 \pm 1.6$ & $242.5 \pm 7.03$ & $112 \pm 2.68$ \\
\hline & III & & 00* & $P=0$ & $00^{*}$ & $P=0$ & 00* & $P=\mathrm{C}$ & $.00^{*}$ & & $.00^{*}$ \\
\hline Pop & & $61.17 \pm 2.71$ & $55.17 \pm 3.19$ & $29.67 \pm 3.2$ & $38.83 \pm 2.31$ & $65.17 \pm 2.79$ & $76.83 \pm 2.48$ & $130 \pm 5.76$ & $48.17 \pm 1.94$ & $133 \pm 2.97$ & $56.5 \pm 2.74$ \\
\hline (H) & $5 \pi$ & & 01* & $P=0$ & $00^{*}$ & $P=0$ & 00* & $P=c$ & $.00^{*}$ & & $.00^{*}$ \\
\hline & H & $67.83 \pm 4.31$ & $64.67 \pm 3.14$ & $22.5 \pm 2.17$ & $36.83 \pm 2.32$ & $69.5 \pm 2.35$ & $84.67 \pm 3.27$ & $88.83 \pm 6.43$ & $52 \pm 2.1$ & $109.5 \pm 5.36$ & $55.5 \pm 3.73$ \\
\hline & Hit & & & $P=0$ & $00^{*}$ & $P=0$ & 00* & $P=c$ & $.00^{*}$ & & $.00^{*}$ \\
\hline & 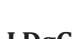 & $237.33 \pm 6.31$ & $262.83 \pm 5.42$ & $168.83 \pm 4.45$ & $92.5 \pm 1.38$ & $577 \pm 6.81$ & $205 \pm 3.52$ & $573.33 \pm 7.45$ & $792.67 \pm 3.67$ & $583.67 \pm 3.98$ & $640.83 \pm 31.52$ \\
\hline & LDgu & & & $P=0$ & $00^{*}$ & $P=0$ & 00* & $P=\mathrm{C}$ & $.00 *$ & & $.06 *$ \\
\hline & Fg & $103.17 \pm 3.31$ & $115.33 \pm 2.8$ & $65.67 \pm 5.28$ & $36.33 \pm 2.94$ & $228 \pm 7.24$ & $91.17 \pm 1.94$ & $250.5 \pm 8.48$ & $344.67 \pm 3.78$ & $244.33 \pm 2.88$ & $282.17 \pm 5.19$ \\
\hline Pop & G & & 00* & $P=0$ & 00* & $P=0$ & 00* & $P=c$ & $.00^{*}$ & & $.00^{*}$ \\
\hline (G) & SD & $44.17 \pm 2.13$ & $46.83 \pm 2.56$ & $27.5 \pm 2.74$ & $22.67 \pm 3.67$ & $97.67 \pm 4.27$ & $49.33 \pm 2.73$ & $88.67 \pm 6.15$ & $133.17 \pm 2.56$ & $105.67 \pm 2.8$ & $111.5 \pm 4.72$ \\
\hline & go & & 00* & $P=0$ & 03* & $P=0$ & 00* & $P=\mathrm{C}$ & $.00 *$ & & $.02 *$ \\
\hline & Da & $87.67 \pm 4.8$ & $119 \pm 39.25$ & $77.33 \pm 3.01$ & $34 \pm 2$ & $251.33 \pm 2.25$ & $65 \pm 1.79$ & $234.17 \pm 4.88$ & $314.83 \pm 2.32$ & $233.67 \pm 3.88$ & $263.83 \pm 4.17$ \\
\hline & LDgu & & 00* & $P=0$ & $00^{*}$ & $P=0$ & 00* & $P=c$ & $.00 *$ & & $.00 *$ \\
\hline
\end{tabular}

*: Significant at $\leq 0.05$. Ag BL: Agranular blast-like cells; FgG: Few-granulated granulocytes; GBL: Granular blast-like cells; LH: Large hyalinocytes; LDgG: Large dense-granulated granulocytes; PO: Post-exposure to S. mansoni; Pop: Population; Pop I (B): Blast-like cells; Pop II (H): Hyalinocytes; Pop III (G): Granulocytes; R: Resistant; S: Susceptible; SDgG: Small dense-granulated granulocytes; Sg: Small granulocytes; SH: Small hyalinocytes; SubPops: Subpopulations; TBL: Total blast-like cells; TH: Total hyalinocytes; THC: Total hemocyte count.

Table 2. Measurements of Giemsa stained B. alexandrina hemocytes.

\begin{tabular}{|c|c|c|c|c|c|}
\hline \multicolumn{3}{|c|}{ Hemocyte sub-population } & Cell dimension $(\mu \mathrm{m})$ & Nucleus dimension $(\mu \mathrm{m})$ & $\mathrm{N} / \mathrm{C}$ ratio \\
\hline \multirow{2}{*}{ Pop I (B) } & & AgBL (Ia) & $4.0 \pm 0.2$ & $3.2 \pm 0.1$ & $0.8 \pm 0.03$ \\
\hline & & GBL (Ib) & $4.0 \pm 0.2$ & $3.2 \pm 0.1$ & $0.8 \pm 0.3$ \\
\hline \multirow{2}{*}{ Pop II (H) } & & SH (IIa) & $4.5 \pm 0.02$ & $2.8 \pm 0.1$ & $0.6 \pm 0.02$ \\
\hline & & LH (IIb) & $6.4 \pm 0.2$ & $2.3 \pm 0.1$ & $0.4 \pm 0.02$ \\
\hline \multirow{3}{*}{ Pop III (G) } & \multirow{2}{*}{ SG (IIIa) } & FgG with lobulated nucleus & $4.4 \pm 0.4$ & $2.4 \pm 0.1$ & $0.5 \pm 0.3$ \\
\hline & & SDgG with blue round nucleus & $5.5 \pm 0.2$ & $1.0 \pm 0.2$ & $0.2 \pm 0.3$ \\
\hline & \multicolumn{2}{|c|}{ LDgG (IIIb) } & $13.5 \pm 0.5$ & $3.5 \pm 0.1$ & $0.3 \pm 0.1$ \\
\hline
\end{tabular}

AgBL: Agranular blast-like cells; FgG: Few-granulated granulocytes; GBL: Granular blast-like cells; H: Hyalinocytes; LDgG: Large dense-granulated granulocytes; LH: Large hyalinocytes; Pop: Population; N/C: Nucleocytoplasmic ratio; SDgG: Small densegranulated granulocytes; SG: Small granulocytes; SH: Small hyalinocytes. There is a statistically significant difference between the different cell populations and subpopulations with regard to N/C ratio $(F=5947.417)$.

Population II: Hyalinocytes $(\mathrm{H})$ were round to oval cells, characterized by their homogenous pale blue cytoplasm, and a basophilic eccentric nucleus (paler and smaller than in blast-like cells). The cytoplasm was full of variably sized vacuoles with no granules nor cytoplasmic extensions (Fig. 4). Hyalinocytes included two subpopulations according to the size of the cell and the nucleus: small hyalinocytes $(\mathrm{SH})$ or subpopulation IIa with a mean diameter of $4.5 \pm 0.02 \mu \mathrm{m}$ and N/C ratio of $0.6 \pm 0.02$ and large hyalinocytes $(\mathrm{LH})$ or subpopulation IIb with a mean diameter of $6.4 \pm 0.02$ $\mu \mathrm{m}$ and $\mathrm{N} / \mathrm{C}$ ratio of $0.4 \pm 0.02$.

Population III: All granulocytes (G) exhibited cytoplasmic granules that sometimes pushed the nucleus to the periphery. Some had the capability of forming prominent pseudopodia or filopodia. They were variable in size and polymorphic, from circular to fusiform. Some showed two nuclei and a dividing cytoplasm representing cell division. They were 
differentiated into:

(a) Small granulocytes (subpopulation IIIa): Those were subdivided according to the staining characteristics and shape of the nucleus into:

- Subpopulation IIIa1 (few small-granulated granulocytes): These were polymorphic; round, oblong to spindle. They were small with a mean diameter of $4.4 \pm 0.4 \mu \mathrm{m}$, and showed small lobulated basophilic nucleus, few basophilic peripheral granules, prominent vacuoles, short and long filopodia and tended to attach (Fig. 5).

-Subpopulation IIIa2 (small dense-granulated granulocytes): These were round cells with a mean diameter of $5.5 \pm 0.2 \mu \mathrm{m}$. They had small round blue nuclei that were centrally located or peripherally
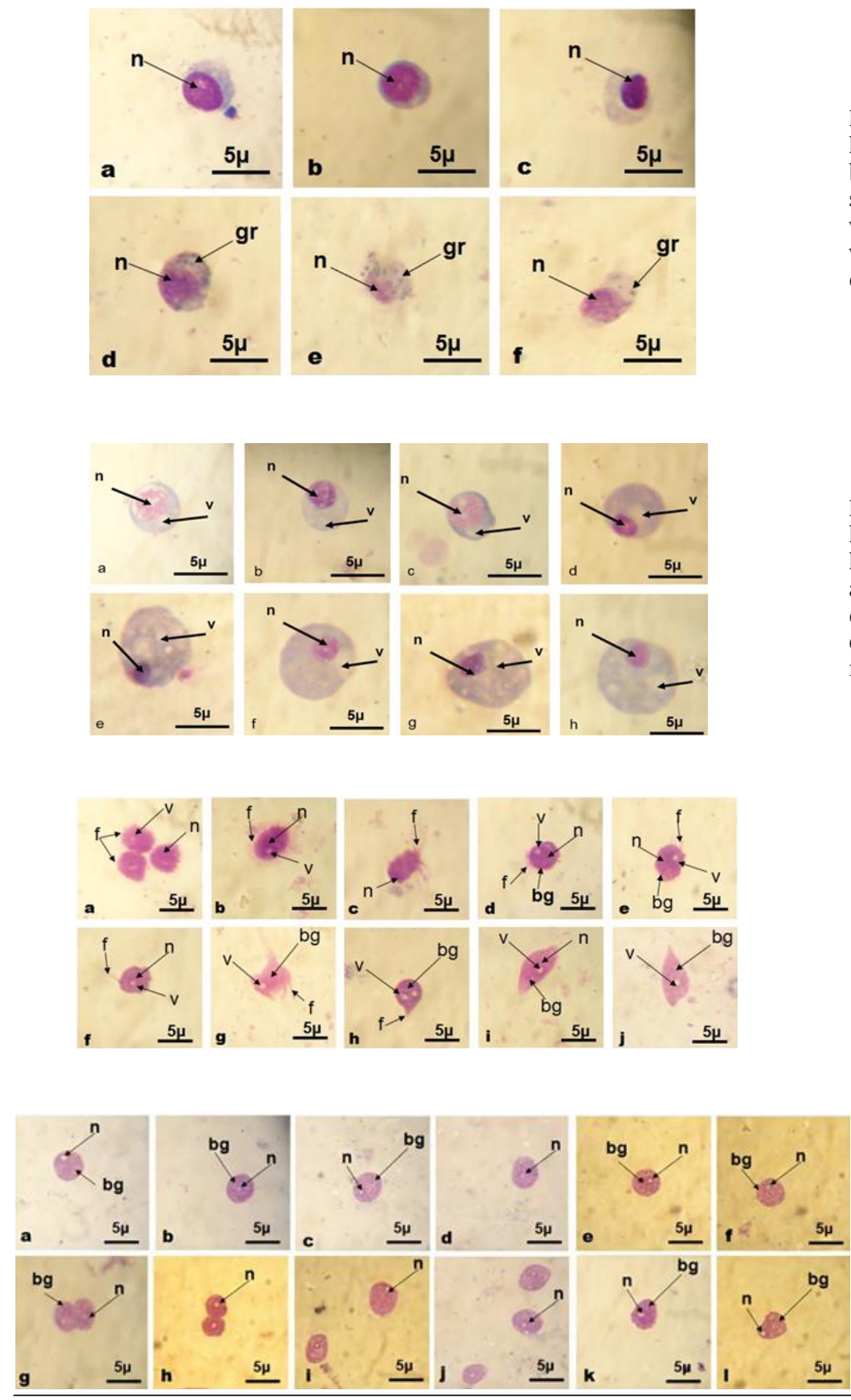

Fig. 6. Light micrographs of Giemsa stained small dense-granulated granulocytes of $B$. alexandrina snails, with round blue stained nucleus and basophilic granules (bg): a-f: regular small granulocytes; $\mathbf{g - h}$ : dividing forms; i: irregular small granulocytes. 
'vacuolated cells' (Fig. 7d). They constituted less than $0.5 \%$ of the THC.

Differential hemocyte counts (DHC): Means of different populations and subpopulations in the susceptible and resistant groups are shown in table (1). Blast-like cells (population I) and their subpopulations showed the least mean among the hemocytes in all studied groups. Conversely, granulocytes (population III) were found to be the most common cell type in

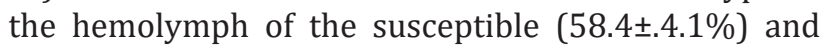
resistant $(61.9 \pm 0.75 \%)$ control snails. Intragroup comparisons for DHC are shown in figure (8) for populations, and in figure (9) for subpopulations.

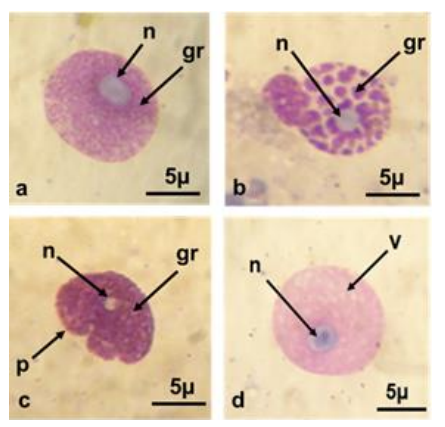

Fig. 7. Light micrographs of Giemsa stained B. alexandrina large granulocytes. a: with fine basophilic granules (gr), nucleus (n); b: with coarse granules (gr), nucleus (n); c: with well-developed pseudopodia (p); d: vacuolated cell with blue-stained nucleus (n) and many vacuoles (v)
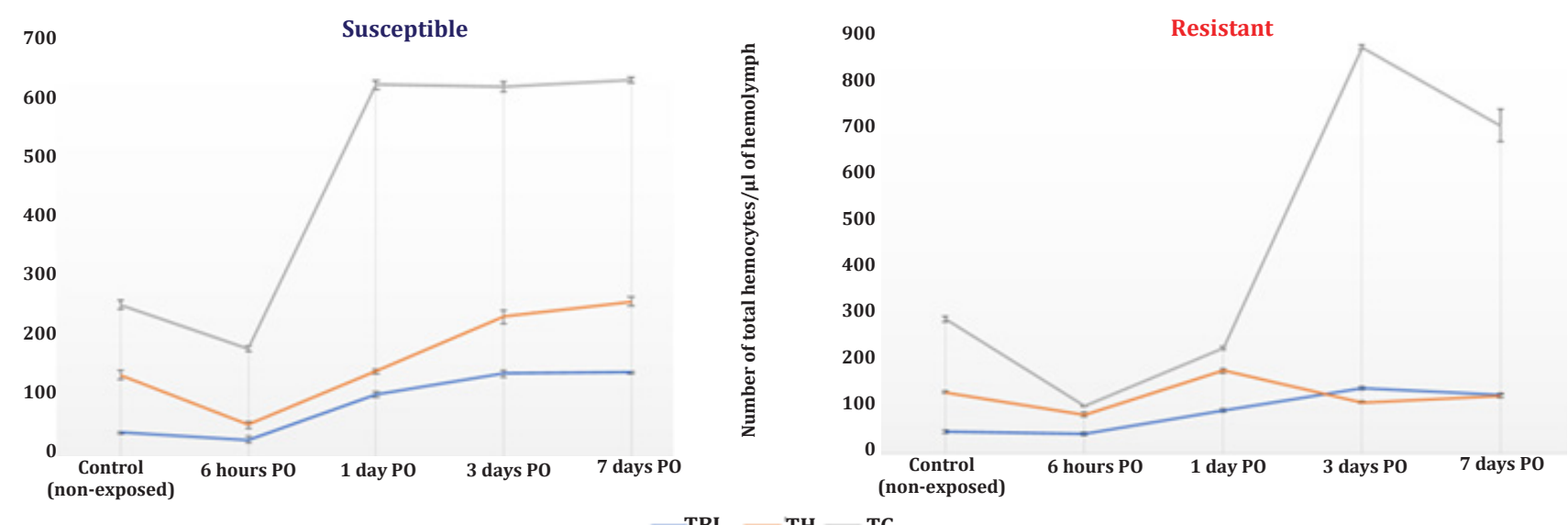

Fig. 8. Comparison of differential hemocyte count (DHC) among susceptible and resistant populations. PO: Post-exposure to $S$. mansoni; TBL: Total blast-like cells; TG: Total granulocytes; TH: Total hyalinocytes.
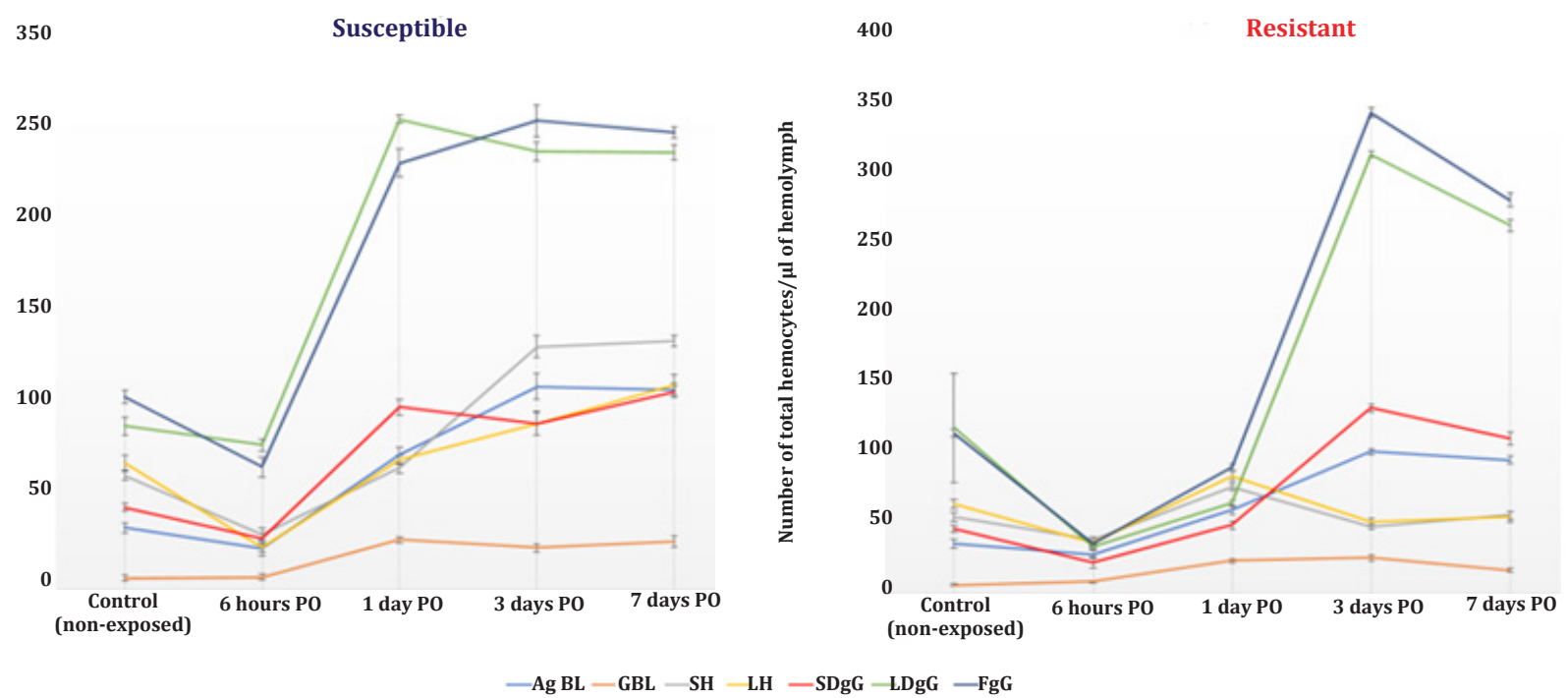

Fig. 9. Comparison of differential hemocyte count (DHC) among susceptible and resistant subpopulations. Ag BL: Agranular blast-like cells; FgG: Few-granulated granulocytes; GBL: Granular blast-like cells; LDgG: Large dense-granulated granulocytes; LH: Large hyalinocytes; PO: Post-exposure to S. mansoni; SDgG: Small dense-granulated granulocytes; SH: Small hyalinocytes. 


\section{DISCUSSION}

The present study confirmed that because of their state of resistance, the THC in the unexposed resistant $B$. alexandrina snails was significantly higher than in the unexposed susceptible snails. This finding followed the report by Walker and Rollinson $^{[26]}$, yet contradicted that of Abaza et al. ${ }^{[13]}$.

The recorded current THC complies with those obtained by Bakry ${ }^{[19]}$ and Osman et al. ${ }^{[27]}$, but are far from the THC obtained by Mohamed ${ }^{[20]}$. Variation in the hemocyte count among different species and even within the same species was previously mentioned ${ }^{[22,28,29]}$. Besides, significant THC differences between the exposed (susceptible and resistant) snails and their controls were observed, at different experimental periods. The only THC reduction in both groups below their controls was achieved at $6 \mathrm{~h}$ PO. This could be explained by hemocyte migration towards the recently attacked tissue. This decrease was noted more in resistant snails. Lockyer et al. ${ }^{[30]}$ attributed the great migratory capacity of resistant hemocytes to the presence of cell surface receptors that bind to the extracellular matrix, thus, enhancing cell migration through the tissues towards the invading pathogens. The investigators found that resistant hemocytes express genes that are related to the actin function, therefore, increasing cellular movements, which are either concerned with the interaction of granulocytes with the parasite or with repair of injured tissues by hyalinocytes following the parasitic invasion ${ }^{[30]}$. A similar early reduction in THC was previously obtained in B. alexandrina ${ }^{[20]}$, B. glabrata $^{[31]}$, and B. tenagophila ${ }^{[28,31]}$. Moreover, an early migration occurred during in vitro interaction between $S$. mansoni sporocysts and Biomphalaria hemocytes $^{[5,9]}$.

Following this early THC reduction, a significant increase at the $1^{\text {st }}$ DPO in both groups was detected especially in the susceptible group. This finding was in agreement with de Melo et al. ${ }^{[32]}$, who stated that the response at the $1^{\text {st }}$ DPO was more potent than the response during earlier stages of host-parasite interaction. According to Araque et al. ${ }^{[33]}$, the early migration of hemocytes to the internal tissues happens regardless of snail-parasite compatibility status. After this stage, the process of parasite infection differs between susceptible and resistant snails, where, resistant snails recognize the parasites as non-self, thus forming a strong connection between snails' hemocytes and the parasite, leading to persistence of the hemocytes in resistant snails' tissues for a longer time than in case of susceptible snails ${ }^{[28]}$. In susceptible snails, hemocytes are activated by the invading parasite, yet, they cannot encapsulate the invader due to absence of lectins that firmly connect the parasite and the hemocytes, thus, they returned to the hemolymph at this time ${ }^{[31]}$.
The increased THC in both groups at the $1^{\text {st }}, 3^{\text {rd }}$, and $7^{\text {th }}$ DPO could be attributed to the production of new hemocytes from the amebocytes producing organ (APO) and other snail hemopoietic centers ${ }^{[16]}$. According to two reports ${ }^{[3,35]}$, S. mansoni extracts maximally stimulate hemocyte production from APO within 48 hours and not earlier. This explains why the current maximum THC elevation was achieved at the $3^{\text {rd }}$ day PO in the resistant group. Similarly, a significant THC increase was recorded at the $3^{\text {rd }}$ and $7^{\text {th }} \mathrm{DPO}^{[27]}$, while others recorded a significant THC reduction at the $7^{\text {th }} \mathrm{DPO}^{[20,29]}$.

Different theories explained hemocyte differentiation. One of them proposes that there is only one blast cell line that gives rise to hyalinocytes, which might later become granulocytes ${ }^{[15,17]}$. Another assumption is the existence of more than one lineage that gives rise to different hemocytes ${ }^{[36,37]}$. The term 'cell population' was implemented herein, instead of 'cell type' because the functional identification of the cell types was not performed ${ }^{[38]}$.

The blast-like cells were the least encountered all through the current experiment in both groups. They showed the same morphology as those belonging to B. glabrata and B. stramine ${ }^{[11]}$, gastropods ${ }^{[17,37]}$, bivalves $^{[39]}$, and other invertebrates ${ }^{[25]}$. Hine $\mathrm{H}^{[15]}$ assumed them to be hemocyte progenitors. In the present work, the recorded unique granular blast-like cells may be the progenitor of future granulocytes.

The hyalinocytes described in this work had the same morphology of hyalinocytes in different mollusks ${ }^{[15,40,41]}$. Barracco et $a .^{[41]}$ and Cheng and Auld ${ }^{[42]}$ noted that the hyalinocytes of B. glabrata and $B$. tenagophila, respectively, were poorly spreading cells in the contrary to granulocytes that readily spread on surfaces. On the other hand, Cavalcanti et al. ${ }^{[11]}$ found many hyalinocytes with filopodia in $B$. glabrata and B. stramenia.

Interestingly, small hyalinocytes currently detected were found to have a higher $\mathrm{N} / \mathrm{C}$ ratio, than large hyalinocytes. According to Donaghy et $a{ }^{[17]}$, the increase in cell size and the decrease in the N/C ratio from small to large indicates cell maturity. Souza Sdos and Andrade ${ }^{[16]}$ described hyalinocytes as immature, small spherical cells, versus granulocytes that exhibited eccentric nuclei and expanded cytoplasm with filopodia.

Granulocytes shown in the present study were detected more in resistant snails ${ }^{[13]}$. They possessed well-developed pseudopodia or filopodia resulting in cell-to-cell clumping ${ }^{[37]}$. They contained many granules similar to those of B. glabrata $^{[14,42]}$, except for granulocytes in subgroup IIIa1 that showed fewer 
granules in agreement with Helal et al. ${ }^{[18]}$. Barracco et $a l^{[41]}$ showed that $B$. tenagophila granulocytes contained few granules. It is noteworthy that granulocytes with two nuclei and a dividing cytoplasm were commonly detected in resistant snails suggesting cell multiplication ${ }^{[13]}$.

Based on their affinity to Giemsa stain, the large granulocytes detected herein contained basophilic or eosinophilic granules, in agreement with Bakry ${ }^{[19]}$. On the other hand, Cavalcanti et al. ${ }^{[11]}$ found that granules in B. glabrata and B. stramenia granulocytes were mostly basophilic. Cheng ${ }^{[14]}$ stated that granules' different staining properties may be explained by $\mathrm{pH}$ changes and ontogenetic an/or metabolic phases within the granulocyte line.

Granulocytes containing large coarse granules were occasionally detected. These cells are known to transport metabolic substances from the digestive glands, or maybe involved in the aggregation $\operatorname{process}^{[40,43]}$.

Vacuolated cells were scarcely detected (less than $0.5 \%)$. They shared morphological similarities with granulocytes, yet lacked granules and possessed many vacuoles. These cells could not be classified before $^{[39]}$. With regards to DHC, blast-like cells showed variations in their count along the whole experiment, possibly because they act as stem cells for other cell populations ${ }^{[44]}$.

Granulocytes are the main cells engaged in snail defense ${ }^{[6,9]}$, thus, variations in their count upon facing parasitic infection are more likely to occur than variations in hyalinocytes' count ${ }^{[28,45]}$. This explains our results which showed that granulocytes were significantly higher in the control resistant snails than the corresponding susceptible snails, while hyalinocytes displayed a reverse profile. Allegretti et $a l_{.}{ }^{[46]}$ attributed the higher resistance of albino $B$. glabrata snails to $S$. mansoni infection to their increased granulocytes count. In the same context, Pila et al. ${ }^{[47]}$ suggested that high granulocytes' count is related to resistance. Working on B. glabrata, Cheng and Auld ${ }^{[42]}$ reported that granulocytes comprised $93 \%$ of THC. Similarly, Barracco et al. ${ }^{[41]}$ stated that B. tenagophila granulocytes represented $90 \%$ of the circulating hemocytes. Conversely, Cavalcanti et $a l^{[11]}$ reported that granulocytes constituted only $4 \%$ of B. glabrata THC and 5\% of B. stramenia THC.

In our study following exposure to $S$. mansoni, hyalinocytes' count decreased within $6 \mathrm{~h}$ in both susceptible and resistant snails. This may be due to their role in tissue repair and coagulation and in their immune response ${ }^{[48]}$. Osman et al. ${ }^{[27]}$ found that hyalinocytes were capable of phagocytosis but, at a less extent than granulocytes.
The granulocyte count decreased $6 \mathrm{~h} \mathrm{PO}$, especially in resistant snails. This decrease was followed by a significant elevation from the $1^{\text {st }}$ DPO in susceptible snails and the $3^{\text {rd }}$ DPO in resistant snails and continued to the $7^{\text {th }}$ DPO in both snail groups. The delay in count elevation in resistant snails could be due to activation of the granulocytes by the parasite excretory-secretory products, with subsequent parasitic migration and adhesion ${ }^{[5,49]}$. The elevation of granulocyte count thereafter could be due to the stimulation of hemopoiesis.

The exposure to $S$. mansoni led to great variations in the number of the granulocytes subpopulations, reflecting differential involvement in the subpopulation response to the parasite. Total granulocytes count has increased at the $3^{\text {rd }}$ and the $7^{\text {th }}$ DPO in resistant snails. The large dense-granulated granulocytes showed the same increase in number highlighting their cytotoxic defense role against the parasite. Degranulation of the granulocytes leads to release of reactive components causing parasite lysis and death ${ }^{[50]}$.

Few-granulated granulocytes showed the same kinetic changes in their number, suggesting that they have the same defense function. This granulocyte subset, in particular, was very reactive upon $S$. mansoni exposure indicating its participation during early parasite destruction. Consequently, granulocytes' subpopulations that were highly reactive against $S$. mansoni in the present study were the few-granulated granulocytes and the largegranulated granulocytes. Martins-Souza et al. ${ }^{[22]}$ proved that these subpopulations are responsible for $S$. mansoni destruction in $B$. tenagophila. Meanwhile, the number of the small dense-granular granulocytes' subpopulation did not show significant changes, compared to the total granulocytes, all through the experiment in susceptible and resistant snails. This could reflect the failure of these cells to participate in immune defense against $S$. mansoni infection. Yoshino et al. ${ }^{[51]}$ demonstrated that small, rounded granulocyte subpopulation in B. glabrata lacks certain glycotopes, which are important for parasite killing.

Interventions targeting the snail hosts are crucial in the integrated strategy required for schistosomiasis elimination and include the recent revolution in gene drive technology, gene editing or clustered, regularly interspaced short palindromic repeats (CRISPR) tools. CRISPR-Cas 9 was recently used to identify and control vector tick embryos' genes, rendering them resistant to Lyme disease, thus decreasing disease transmission ${ }^{[52,53]}$. This technique could help spread schistosome resistance traits in snails' population, thus, reducing schistosomiasis transmission in the long run ${ }^{[52]}$. 
In conclusion, the current study reveals differences in the kinetic response of hemocytes between susceptible and resistant snails during the first week after exposure to $S$. mansoni. The differential responses at this critical period are related to the host-parasite interactions with subsequent effects on the parasite propagation inside the snail. Hemograms obtained could help in determining the participation of each cell population and subpopulation in the defense response against $S$. mansoni infection. This would serve as useful background data for future studies concerning Biomphalaria hemopoiesis and ontogenesis. Better understanding of the snail compatibility patterns allows the developing of new modalities that enhance hemocyte activity that increases resistance to infection. Further studies to utilize gene editing techniques and CRISPR-Cas9 technique for propagation of transgenic strains of $B$. alexandrina snails are required to spread schistosome resistance traits in snails' population, thus, contributing to reduced schistosomiasis transmission in the long run.

Acknowledgment: The author is much obliged to Professor Dr. Iman Abou-El-Naga for her great help in this work. Thanks are extended to Dr. Marwa El Faham, a native English-speaking parasitologist, for her help in the English editing of this article.

Conflict of interest statement: There is no actual nor potential conflict of interest including any financial, personal, or other relationships with other people or organizations that could inappropriately influence or be perceived to influence this work.

Funding statement: This research did not receive any specific grant from funding agencies in the public, commercial, or not-for-profit sectors.

\section{REFERENCES}

1. Colley DG, Bustinduy AL, Secor WE, King CH. Human schistosomiasis. Lancet 2014; 383: 2253-2264.

2. Abou-El-Naga IF, El-Nassery SM, Allam SR, Shaat EA, Mady RF. Biomphalaria species in Alexandria water channels. Parasitol Int 2011; 60(3): 247-254.

3. Markell EK, Voge M. The Blood Flukes: Schistosoma mansoni. In: Medical Parasitology, 9th ed. Philadelphia, WB Saunders Company, 2006; 183-184.

4. Abou-El-Naga IF, Sadaka HA, Amer EI, Diab IH, Khedr SIA. Impact of Biomphalaria alexandrina snails`age on transmission of Schistosoma mansoni: Modulation of the genetic outcome and the internal defense system of the snail. Mem Inst Oswaldo Cruz 2015;110 (5): 585-595.

5. Nacif-Pimenta R, de Mattos AC, Orfanó Ada S, Barbosa L, Pimenta PF, Coelho PM. Schistosoma mansoni in susceptible and resistant snail strains Biomphalaria tenagophila: in vivo tissue response and in vitro hemocyte interactions. PloS One 2012; 7(9): e45637.

6. Negrão-Corrêa D, Pereira CAJ, Rosa FM, Martins-Souza RL, Andrade ZA, Coelho PMZ. Molluscan response to parasite: Biomphalaria and Schistosoma mansoni interaction. Invert Surviv J 2007; 4: 101-111.

7. Loker ES. Gastropod immunobiology. Adv Exp Med Biol 2010; 708: 17-43.

8. Abou-El-Naga IF, Radwan EH. Defense response of susceptible and resistant Biomphalaria alexandrina snails against Schistosoma mansoni infection. Rev Biol Trop 2012; 60 (3): 1195-1204.

9. Abou-El-Naga IF, El-Nassery SMF, Allam SR, Mady RF. In vitro interactions between the defense systems of resistant and susceptible Biomphalaria alexandrina and sporocysts of Schistosoma mansoni. Vet Parasitol 2014; 205: 712-716.

10. Pila EA, Sullivan JT, Wu XZ, Fang J, Rudko SP, Gordy $\mathrm{MA}$, et al. Hematopoiesis in molluscs: a review of hemocyte development and function in gastropods, cephalopods and bivalves. Dev Comp Immunol 2016; 58: 119-128.

11. Cavalcanti MG, Filho FC, Mendonça AM, Duarte GR, Barbosa CCGS, et al. Morphological characterization of hemocytes from Biomphalaria glabrata and Biomphalaria straminea. Micron 2012; 43(2-3): 285291.

12. Mitta G, Adema CM, Gourbal B, Loker ES, Theron A. Compatibility polymorphism in snail/schistosome interactions: from field to theory to molecular mechanisms. Dev Comp Immunol 2012; 37: 1-8.

13. Abaza BE, Hamza RS, Farag TI, Abdel-Hamid MA, Moustafa RA. Characterization of the hemocytes of susceptible and resistant Biomphalaria alexandrina snail. J Egypt Soc Parasitol 2016; 46(3): 671-682.

14. Cheng TC. Functional morphology and biochemistry of molluscan phagocytes. Ann N Y Acad Sci 1975;266: 343-379.

15. Hine PM. The inter-relationships of bivalve hemocytes. Fish Shellfish Immunol 1999; 9: 367-385.

16. Souza Sdos S, Andrade ZA. The significance of the amoebocyte-producing organ in Biomphalaria glabrata. Mem Inst Oswaldo Cruz 2012; 107(5): 598603.

17. Donaghy L, Hong HK, Lambert C, Park HS, Shim WJ, Choi KS. First characterization of the populations and immune-related activities of hemocytes from two edible gastropod species, the disk abalone, Haliotis discus discus and the spiny top shell, Turbo cornutus. Fish Shellfish Immunol 2010; 28: 87-97.

18. Helal IB, ELMehlawy MH, Rizk ET, EL-Khodary GM. Effect of Euphorbia peplus plant extract and the antihelmenthic prazequantel on the defence system of Biomphalaria alexandrina snail. Egypt J Aq Biol Fisheries 2003; 7: 501-527.

19. Bakry FA. Effect of infection with Schistosoma mansoni on some biological parameters in Biomphalaria alexandrina snails. AEJSR 2009;4: 180-190.

20. Mohamed AH. Sublethal toxicity of roundup to immunological and molecular aspects of Biomphalaria 
alexandrina to Schistosoma mansoni infection. Ecotoxicol Environ Saf 2011; 74(4): 754-760.

21. Abdel-Hamid H, Mekawey AA. Biological and hematological responses of Biomphalaria alexandrina to mycobiosynthsis silver nanoparticles. J Egypt Soc Parasitol 2014; 44(3): 627-237.

22. Martins-Souza RL, Pereira CA, Coelho PM, MartinsFilho OA, Negrão-Corrêa D. Flow cytometry analysis of the circulating hemocytes from Biomphalaria glabrata and Biomphalaria tenagophila following Schistosoma mansoni infection. Parasitol 2009; 136: 67-76.

23. Portet A, Pinaud S, Chaparro C, Galinier R, Dheilly NM, Portela J et al. Sympatric versus allopatric evolutionary contexts shape differential immune response in Biomphalaria/Schistosoma interaction. PLoS Pathog 2019;15(3):e1007647.

24. Fallon PG, Fookes RE, Doenhoff MJ. Protection of mice against Schistosoma mansoni infection by passive transfer of sera from infected rabbits. Parasite Immunol 1996; 18: 7-14.

25. Brayner FA, Araujo HRC, Cavalcanti MGS, Alves LC, Peixoto CA. Ultrastructural characterization of the hemocytes of Culex quinquefasciatus (Diptera: Culicidae). Micron 2005; 36: 359-367.

26. Walker AJ, Rollinson D. Specific tyrosine phosphorylation induced in Schistosoma mansoni miracidia by haemolymph from schistosome susceptible, but not resistant, Biomphalaria glabrata. Parasitol 2007; 135(3): 337-345.

27. Osman AM, Gomaa M, Saad AH. Biomphalaria alexandrina: cellular responses of susceptible and resistant snails to Schistosoma mansoni infection. J Egypt Soc Parasitol 2003; 33(3): 805-827.

28. Oliveira AL, Levada PM, Zanotti-Magalhaes EM, Magalhães LA, Ribeiro-Paes JT. Differences in the number of hemocytes in the snail host Biomphalaria tenagophila, resistant and susceptible to Schistosoma mansoni infection. Genet Mol Res 2010; 21: 24362445.

29. Santos DVV, Santos MAV, de Carvalho Rodrigues IR. Hemocyte production in Biomphalaria glabrata snails after exposure to different Schistosoma mansoni infection protocols. Rev Pan-Amaz Saude 2011; 2(2): 33-38.

30. Lockyer AE, Emery AM, Kane RA, Walker AJ, Mayer CD , Mitta G, et al. Early differential gene expression in haemocytes from resistant and susceptible Biomphalaria glabrata strains in response to Schistosoma mansoni. PLoS One 2012;7(12)e51102.

31. Bezerra FSM, Nogueira-Machado JA, Chaves MM, Martins RL, Coelho PMZ. Quantification of the number and phagocytary activity of hemocytes of resistant and susceptible strains of Biomphalaria glabrata and Biomphalaria tenagophila infected with Schistosoma mansoni. Rev Inst Med Trop Sao Paulo 1997; 39: $197-$ 201.

32. de Melo ES, Brayner FA, Junior NCP, França IRS, Alves LC. Investigation of defense response and immune priming in Biomphalaria glabrata and Biomphalaria straminea, two species with different susceptibility to
Schistosoma mansoni. Parasitol Res 2020; 119(1): 189201.

33. Araque W, Barrios EE, Rodríguez P, Delgado VS, Finol HJ. Ultrastructural study of the in vitro interaction between Biomphalaria glabrata hemocytes and Schistosoma mansoni miracidia. Mem Inst Oswaldo Cruz 2003; 98(7): 905-908.

34. Sullivan JT, Pikios SS, Alonzo AQ. Mitotic responses to extracts of miracidia and cercariae of Schistosoma mansoni in the amebocyte-producing organ of the snail intermediate host Biomphalaria glabrata. J Parasitol 2004; 90: 92-96.

35. Barbosa L, Silva LM, Coelho PMZ, Santos SR, Fortes-Dias CL. Primary culture of the region of the amebocyteproducing organ of the snail Biomphalaria glabrata, the intermediate host of Schistosoma mansoni. Mem Inst Oswaldo Cruz 2006; 101: 639-643.

36. Ottaviani E, Franchini A, Barbieri D, Kletsas D. Comparative and morpho-functional studies on Mytilus galloprovincialis hemocytes: presence of two aging-related hemocyte stages. Ital J Zool 1998; 65: 349-354.

37. Mahilini HM, Rajendran A. Categorization of hemocytes of three gastropod species Trachea vittata (Muller), Pila globosa (Swainson) and Indoplanor bisexustus (Dehays). J Invert Pathol 2008; 97: 20-26.

38. Accorsi A, Bucci L, de Eguileor M, Ottaviani E, Malagoli D. Comparative analysis of circulating hemocytes of the freshwater snail Pomacea canaliculata. Fish Shellfish Immunol 2013; 34(5): 1260-1268.

39. Chang SJ, Tseng SM, Chou HY. Morphological characterization via light and electron microscopy of the hemocytes of two cultured bivalves: A comparison study between the hard clam (Meretrix lusoria) and Pacific oyster (Crassostrea gigas). Zoo Stud 2005; 44: 144-152.

40. Yonow N, Renwrantz, L. Studies on the hemocytes of Acteon tornatilis (L.) (Opisthobranchia: Acteonidae). J Moll Stud 1986; 52: 150-155.

41. Barracco MA, Steil AA, Gargioni R. Morphological characterization of the hemocytes of the pulmonate snail Biomphalaria tenagophila. Mem Inst Oswaldo Cruz 1993; 88(1): 73-83.

42. Cheng TC, Auld KR. Hemocytes of the pulmonate gastropod Biomphalaria glabrata. J Invert Pathol 1977; 30: 119-122.

43. Nakayama K, Nomoto AM, Nishijima M, Maruyama T. Morphological and functional characterization of hemocytes in the Giant Clam Tridacna crocea. J Invert Pathol 1997; 69: 105-111.

44. Aladaileh S, Nair SV, Birch D, Raftos DA. Sydney rock oyster (Saccostrea glomerata) hemocytes: morphology and function. J Invert Pathol 2007; 96(1): 48-63.

45. Seta L, Magalhães LA, Carvalho JF. Behavior of hemolymph amebocytes from Planorbidae in the presence of Schistosoma mansoni larvae parasitism, by inoculation of Indian ink or fracture of the shell. Rev Saúde Pública 1996;30: 332-340.

46. Allegretti SM, Carvalho JF, Magalhães LA, ZanottiMagalhães EM. Behavior of albino and melanic 
variants of Biomphalaria glabrata Say, 1818 (Mollusca: Planorbidae) following infection by Schistosoma mansoni Sambon, 1907. Braz J Biol 2009; 69(1): 217 222.

47. Pila EA, Li H, Hambrook JR, Wu X, Hanington PC. Schistosomiasis from a snail's perspective: advances in snail immunity. Trends Parasitol 2017; 33:845-857.

48. Hégaret H, Wikfors GH. Time-dependent changes in hemocytes of eastern oysters, Crassostrea virginica, and northern bay scallops, Argopecten irradians irradians, exposed to a cultured strain of Prorocentrum minimum. Harmful Algae 2005 ; 4(2): 187-199.

49. Zahoor Z, Davies AJ, Kirk RS, Rollinson D, Walker AJ. Larval excretory-secretory products from the parasite Schistosoma mansoni modulate HSP70 protein expression in defense cells of its snail host, Biomphalaria glabrata. Cell Stress Chaperon 2010; 15: 639-650.
50. Li CW, Shields JD. Primary culture of hemocytes from the Caribbean spiny lobster, Panulirus argus, and their susceptibility to Panulirus argus virus 1 (PaV1). J Invert Pathol 2007; 94,48e55.

51. Yoshino TP, Wu XJ, Gonzalez LA, Hokke CH. Circulating Biomphalaria glabrata hemocyte subpopulations possess shared schistosome glycans and receptors capable of binding larval glycoconjugates. Exp Parasitol 2013; 133(1): 28-36.

52. Maier T, Wheeler NJ, Namigai EKO, Tycko J, Grewelle RE, Woldeamanuel Y, et al. Gene drives for schistosomiasis transmission control. PLoS Negl Trop Dis 2019;13(12): e0007833.

53. Gulia-nuss M. Non-model organism research in the changing genomic landscape: Editorial. PUJ 2019; 12(1): 1-2. 